\title{
Avaliação de diferentes manejos pré-parto sobre o peso e o escore da condição corporal de vacas mestiças F1 Holandês x Zebu*
}

\section{Evaluation of different prepartum diets on weight and body condition score of F1 crossbred Holstein x Zebu cows}

\author{
Bruno Campos de Carvalho, ${ }^{* *}$ José Reinaldo Mendes Ruas, ${ }^{* * *}$ José Monteiro da Silva Filho, ${ }^{* * *}$ \\ José Joaquim Ferreira, ${ }^{* * * *}$ Martinho de Almeida e Silva, ${ }^{* * * * *}$ Gustavo Chamon de Castro Menezes ${ }^{\star * * * \star * *}$
}

\begin{abstract}
Resumo
Avaliaram-se diferentes variávies biométricas de vacas mestiças $\mathrm{F} 1$ Holandês $\times$ Zebu de diferentes bases genéticas maternas, suplementadas com concentrado (T1) ou não (T2) durante o pré-parto, durante as estações chuvosa e seca. A suplementação no pré-parto, durante a estação chuvosa, aumentou o peso ao parto e os escores da condição corporal ao final do pré-parto e ao parto. Entretanto, não houve diferença entre as vacas suplementadas ou não no ganho de peso total ou diário durante o pré-parto. Durante a estação seca, apesar da suplementação não ter afetado o peso ao parto, ela aumentou o escore da condição corporal ao final do período pré-parto e ao parto. Durante a estação chuvosa, as vacas de base Guzerá apresentaram maior peso corporal final do pré-parto em relação às de base Gir ou Indubrasilada, enquanto que, na estação seca, as vacas de base Guzerá foram mais no início e ao final do pré-parto e também ao parto. A suplementação no pré-parto, em vacas mestiças, deve ser usada de forma estratégica, com o intuito de aumentar o escore da condição corporal ao parto, especialmente durante a estação chuvosa.
\end{abstract}

Palvras-chave: cruzamento, gado de leite, ganho de peso, condição corporal.

\begin{abstract}
It was evaluated different biometric variables of crossbred F1 Holstein $\times$ Zebu cows supplemented or not with concentrate during the transition period, during the dry and the rainy season. The supplementation increased the weitgh and body condition score at the end of the transition period and at calving, although there was not difference in the total and daily weight gains. During the dry season the supplementation did not affect the weight at calving. In the other hand, the supplemented cows presented higher body condition scores at the end of the transition period and at calving. During the rainy season, Guzera based cows had higher weights at the end of the transition period and at calving than the Gir or Indubrasil based cows. The supplemetation of crossbred dairy cows during the transition period must be done strategically, specially during the rainy season.
\end{abstract}

Keywords: crosses, dairy cattle, weight at calving, body condition score.

\section{Introdução}

Em Minas Gerais, a produção de leite/vaca/ano é em média de $1463 \mathrm{~kg}$ (Zoccal, 2009). Essa produção é oriunda de um rebanho em que $41,71 \%$ das vacas ordenhadas são mestiças Holandês $\times$ Zebu, 24,89\% têm predominância de sangue Holandês (mais que 7/8 Holandês $\times$ Zebu), 7,95\% têm predominância de sangue Zebu e 25,45\% não apresentam padrão definido quanto ao grau de sangue (Faemg, 2006). Em sistemas de produção de leite com gado mestiço, predomina o uso de pastagens durante a estação chuvosa e a suplementação com volumoso na estação seca do ano. Essa variação na oferta de alimentos ao longo do ano implica manejo inadequado, uma vez que influencia, de forma determinante, a produção e reprodução dos animais. O período de transição, especialmente o manejo pré-parto, vem recebendo pouca atenção em vacas mestiças em relação à recebida pelas vacas especializadas de alta produção. Durante esse período, as vacas passam por profundas mudanças metabólicas. O fim da gestação e o

\footnotetext{
* Apoio: CNPq e Fapemig (CAG 803/05)

** Pesquisador, Epamig, Juiz de Fora - MG. A quem enviar correspondência: bccarvalho@epamig.br.

*** Pesquisador, Epamig, Belo Horizonte - MG, jrmruas@epamig.br

**** Professor associado, Escola de Veterinária, UFMG, Belo Horizonte - MG, monteiro@vet.ufmg.br

***** Pesquisador, Epamig, Prudente de Morais - MG, ferreira@epamig.br

***** Professor associado, Escola de Veterinária, UFMG, Belo Horizonte - MG, martinho@vet.ufmg.br

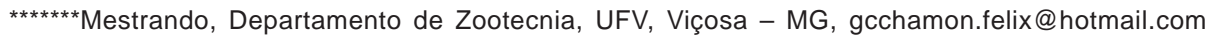


início da lactação promovem intensa modificação do perfil hormonal e metabólico do animal, que tem que se adaptar a uma nova fase. Aditivamente, ocorrem alguns eventos, como a redução da ingestão de matéria seca e o início do período de balanço energético negativo. $O$ manejo nutricional na fase pré-parto deve ser realizado visando-se maximizar a produção de leite e a eficiência reprodutiva, bem como reduzir a incidência de doenças no início da lactação.

Em vacas mestiças mantidas a pasto existem poucas informações disponíveis sobre os efeitos do manejo nutricional no pré-parto sobre o seu desempenho. Além disso, essas vacas sofrem mudança profunda no seu manejo nutricional ao longo do ano. Durante a estação chuvosa, são mantidas a pasto, embora recebam suplementação volumosa durante a estação seca. Essas duas estações do ano estão associadas a duas situações nutricionais distintas, que podem afetar a produtividade da vaca, principalmente durante a estação chuvosa, quando a qualidade do volumoso, ou seja, as pastagens, são variáveis ao longo do período.

Uma importante consideração a ser feita refere-se às diferenças na deposição de gordura, entre raças de leite e corte. Vacas de raças leiteiras, tais como a Holandesa e a Jersey apresentam maior deposição de gordura visceral (omental e perirrenal), quando comparadas às vacas oriundas de raças de corte (Angus e Brahman), que apresentam maior deposição de gordura subcutânea. Além disso, ao avaliar-se a exigência nutricional de diferentes raças e seus cruzamentos, observou-se maior exigência de mantença nas raças leiteiras, que apresentaram maior peso visceral, associado, também, a uma maior exigência de mantença da gordura visceral, com valores intermediários em seus cruzamentos. Além disso, observou-se que a gordura visceral pode ser mobilizada de forma mais rápida e em maiores quantidades do que a subcutânea. Sugere-se ainda, que menores exigências energéticas em fêmeas da raça Brahman estão associadas à deposição de gordura subcutânea, ao invés da visceral, bem como ao menor peso visceral (Thompson et al., 1983; Ferrel e Jenkins, 1984; Ferrel e Jenkins, 1985; Solis et al., 1988; Ferrel e Jenkins, 1998).

Os objetivos do presente trabalho foram avaliar o efeito de dois manejos nutricionais durante o pré-parto sobre diferentes variáveis biométricas de vacas mestiças $F 1$ Holandês x Zebu, de diferentes bases genéticas maternas, durante as estações chuvosa e seca.

\section{Material e métodos}

O experimento foi realizado na Fazenda Experimental de Felixlândia, da Empresa de Pesquisa Agropecuária de Minas Gerais, localizada no município de Felixlândia - MG, que apresenta clima caracterizado por inverno seco (estação seca) e verão chuvoso (estação chuvosa). Foram utilizadas 78 vacas F1 Holandês x Zebu pluríparas, oriundas do cruzamento de touros da raça Holandês com vacas das bases genéticas Gir, Guzerá e com sangue de Indubrasil (Indubrasilada). Na primeira fase do experimento, a saber, a estação chuvosa, foram utilizadas 42 vacas, com partos previstos para o intervalo de dois de janeiro a 31 de março de 2006. Na segunda fase, a estação seca, utilizaram-se 36 vacas com partos previstos para o intervalo de 20 de maio a 15 de agosto de 2006.
As vacas, a cada estação, foram homogeneamente divididas de acordo com a base genética materna e ordem de parto, em dois tratamentos:

T1 - Vacas suplementadas durante o período pré-parto, T2 - Vacas não suplementadas durante o período pré-parto.

Semanalmente, às sextas-feiras, identificavam-se todas as vacas com 30 a 37 dias pré-parto (data provável). A seguir, as mesmas eram submetidas a cada um dos dois manejos pré-parto estabelecidos, que incluíam suplementação (T1) ou não (T2) com concentrado. No dia da entrada no experimento e, semanalmente, sempre no mesmo horário, todas as vacas do pré-parto eram pesadas e avaliadas quanto ao escore da condição corporal. A avaliação do escore da condição corporal foi realizado por inspeção e palpação da garupa, íleos, ísqueos e regiões lombar e costal, atribuindo-se o escore numa escala de 1 a 5 , onde 1 é uma vaca magra e 5 uma vaca gorda.

Durante a estação chuvosa, as vacas permaneceram em pastagens mistas de Brachiaria decumbens e B. brizantha, num sistema de rodízio de piquetes. O tempo de permanência das vacas em cada piquete foi variável, de acordo com a disponibilidade de pastagem. Todas as vacas receberam mistura mineral à vontade.

As vacas do $\mathrm{T} 1$ foram suplementadas com dois quilos de concentrado ( $15 \%$ de PB, $75 \%$ de NDT, $0,5 \%$ de $\mathrm{Ca}$ e $0,8 \%$ de P) por vaca/dia, em grupo. O concentrado foi oferecido em cochos coletivos localizados nos piquetes, às dez horas da manhã. As vacas do grupo não suplementado (T2) tiveram a pastagem como alimento exclusivo e todas as vacas ( $\mathrm{T} 1 \mathrm{e}$ T2) receberam suplementação mineral à vontade.

Durante a estação seca, as vacas receberam silagem de milho como suplementação volumosa. As vacas foram alocadas em dois piquetes maternidade, dotados de bebedouro e cochos para volumoso e sal mineral, que foi fornecido à vontade. Houve rodízio semanal dos piquetesmaternidade entre o grupo suplementado $(\mathrm{T} 1)$ e 0 não suplementado (T2) com concentrado. Assim como na estação chuvosa, foram fornecidos dois quilos por vaca/dia do mesmo concentrado utilizado anteriormente. Todas as vacas foram suplementadas uma vez por dia com silagem de milho à vontade, acrescida de suplemento mineral com $55 \%$ de ureia (concentrado nitromineral) (Ferreira, 2004). A quantidade fornecida foi ajustada para sobras entre 3 e $5 \%$.

Os piquetes-maternidade eram localizados próximos ao curral, de forma a facilitar a observação das vacas no dia do parto. As vacas foram observadas pelo menos duas vezes ao dia, pela manhã e à tarde. No dia do parto, as vacas foram pesadas e avaliadas quanto ao escore da condição corporal.

Foram avaliados o peso e o escore da condição corporal ao início e fim do período pré-parto e ao parto, o ganho de peso total e diário no pré-parto e os dias de permanência no préparto. Devido a diferença no número de animais das diferentes bases maternas em cada época do ano, foram realizadas análises estatísticas para cada época, separadamente. Os pesos avaliados, bem como o ganho de peso total e diário e os dias de permanência na maternidade foram submetidos a análise de variância, utilizando-se modelo linear em que foram considerados os efeitos fixos de tratamento, base genética materna e sua interação dupla. 
As médias foram comparadas pelo teste Student Newman Keuls (SNK) $(P<0,05)$. O escore da condição corporal foi submetido a análise não paramétrica, pelo teste de Wilcoxon ou Kruskal-Wallis. Foi utilizado o programa estatístico SAEG, v. 9.1, da Universidade Federal de Viçosa.

\section{Resultados e discussão}

São apresentados, na Tabela 1, os valores médios de peso e escore da condição corporal no início do período pré-parto de vacas mestiças F1 Holandês x Zebu (HZ) utilizadas no experimento. Durante a estação chuvosa, não se observou diferença $(P>0,05)$ de peso e escore da condição corporal entre os tratamentos e bases genéticas maternas, cuja média foi $553,40 \pm 48,29 \mathrm{~kg}$ e $3,44 \pm 0,23$, respectivamente (Tabela 1). Por outro lado, durante a estação seca, observouse diferença de peso entre as bases genéticas, com as vacas de base Guzerá sendo mais pesadas $(P<0,05)$ que as de base Gir e Indubrasilada (Tabela 1 ). O peso médio de entrada dos animais no pré-parto foi de 537,64 $\pm 59,28,611,00 \pm 65,99$ e $544,00 \pm 30,36 \mathrm{~kg}$, respectivamente, para as vacas das bases genéticas Gir, Guzerá e Indubrasilada. O escore da condição corporal no início do pré-parto foi $3,80 \pm 0,34$, semelhante $(P>0,05)$ entre os tratamentos e bases genéticas maternas (Tabela 1).

Com relação ao peso no final do pré-parto, na estação chuvosa, as vacas de base Guzerá foram mais pesadas $(P<0,05)$ do que as de bases Gir e Indubrasilada (Tabela 2). Durante a estação seca, observou-se comportamento semelhante, sendo que as vacas de base Guzerá também foram mais pesadas $(P<0,05)$ (Tabela 3$)$. Com relação ao escore da condição corporal ao final do pré-parto, observouse efeito da suplementação, nas duas épocas do ano. Durante a estação chuvosa, as vacas suplementadas (T1) apresentaram escore da condição corporal 3,89 $\pm 0,37$, enquanto as vacas não suplementadas apresentaram menor $(P<0,05)$ escore, 3,61 $\pm 0,34$ (Tabela 2$)$. De maneira semeIhante, durante a estação seca, as vacas suplementadas apresentaram maior $(P<0,05)$ escore da condição corporal do que as não suplementadas, que foram, respectivamente,

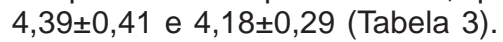

Durante a estação chuvosa, a permanência média na maternidade foi de $37,43 \pm 6,29$ dias e também não diferiu $(P>0,05)$ entre os tratamentos (Tabela 2$)$. Durante essa permanência, o ganho total de peso foi de $49,02 \pm 24,79 \mathrm{~kg}$, o

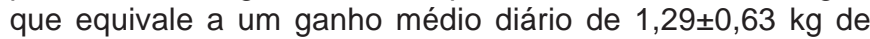
peso (Tabela 2). Explica-se o aumento do escore da condição corporal durante o período pré-parto, que passou de

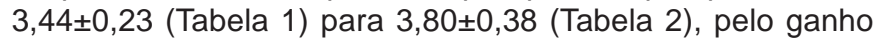
de peso observado no período. Por outro lado, durante a estação seca, a permanência média no período pré-parto foi de $36,19 \pm 14,25$ dias, com ganhos de peso total e diário de $62,35 \pm 28,46 \mathrm{~kg}$ e 1,88 $\pm 1,18 \mathrm{~kg} /$ dia. Não houve diferenças $(P>0,05)$, para essas variáveis, entre os tratamentos (Tabela 3). Durante a estação seca, a condição corporal passou de

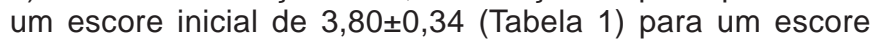

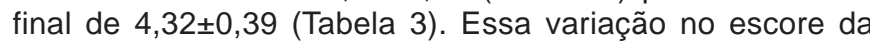
condição corporal justifica-se pela suplementação fornecida, bem como pela maior deposição de gordura subcutânea em relação à visceral, que ocorre em zebuínos e seus mestiços (Ferrel e Jenkins, 1998).
Durante a estação chuvosa não se observou efeito $(P>0,05)$ da base genética com relação ao peso ao parto. Entretanto, a suplementação no pré-parto aumentou $(\mathrm{P}<0,05)$ o peso ao parto. As vacas suplementadas no pré-parto pesaram $541,21 \pm 52,38 \mathrm{~kg}$ ao parto, enquanto as não suplementadas

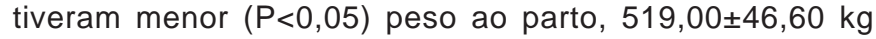
(Tabela 4). Com relação ao escore da condição corporal, ao parto mantiveram-se as diferenças observadas ao final do pré-parto. As vacas suplementadas, além de mais pesadas, tiveram maior $(P<0,05)$ escore da condição corporal ao parto do que as não suplementadas, que foi, respectivamente, $3,93 \pm 0,40$ e $3,58 \pm 0,32$.

Na estação seca não se observou efeito $(P>0,05)$ dos tratamentos sobre o peso corporal, que foi, em média, $541,86 \pm 56,08 \mathrm{~kg}$ (Tabela 4). Por outro lado, observaram-se diferenças entre as bases genéticas maternas utilizadas. As vacas de Guzerá apresentaram maior $(P<0,05)$ peso ao parto em relação às de base Gir, mas semelhantes às de base Indubrasilada, que foram 533,05 $\pm 55,59,590,17 \pm 63,71$ e $531,22 \pm 37,58 \mathrm{~kg}$, respectivamente. De forma semelhante ao observado na estação chuvosa, na estação seca a suplementação também influiu na condição corporal ao parto. As vacas suplementadas (T1) apresentaram escore

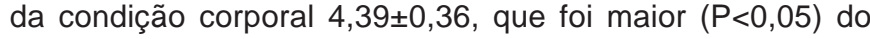
que o escore das vacas não suplementadas, que foi $4,17 \pm 0,29$.

Os resultados apresentados mostram que a suplementação durante o pré-parto promoveu aumento do peso ao final do período pré-parto e ao parto. Quando se consideram as exigências nutricionais de uma vaca ao final da gestação, Bell (1995) as compara com as exigências de uma vaca produzindo de seis a oito quilos diários de leite. De acordo com Ferreira (2004), durante a estação chuvosa, nos meses de dezembro a fevereiro, quando as pastagens geralmente apresentam alto valor nutritivo, o suprimento de nutrientes pelo pasto suporta uma produção de até 12 quilos de leite diários. Assim, ainda que durante o período pré-parto avaliado as pastagens por si tenham atendido aos requisitos nutricionais dessa fase, a suplementação foi capaz de aumentar o peso e o escore da condição corporal ao parto.

Apesar das diferenças observadas de peso e escore da condição corporal ao parto, com relação ao ganho de peso total e diário durante o período, não foi observada diferença entre os tratamentos. Um efeito que deve ser considerado é o de substituição, que ocorre quando se suplementam animais a pasto com concentrados. Nessa situação, o fornecimento de concentrado, muitas vezes, aumenta o consumo de matéria seca total pelo animal. Contudo, ocorre redução da ingestão de matéria seca originada do pasto, que é o efeito de substituição, de forma que o aumento no consumo total de matéria seca é menor do que a quantidade de matéria seca fornecida via concentrado (Stockdale e Trigg, 1989). Por outro lado, a suplementação com silagem de milho, acrescida de concentrado nitromineral, apresenta valor nutritivo superior àquele exigido por vacas em final de lactação, o que pode gerar ganho de peso excessivo (Ferreira, 2004). Dessa forma, apesar de na estação seca a própria silagem tenha atendido aos requisitos nutricionais, a suplementação aumentou o peso corporal, com aumento da deposição de gordura, visualizado pelo aumento do escore da condição corporal ao final do período pré-parto e ao parto. 
Tabela 1: Peso $(\mathrm{kg})$ e escore da condição corporal (ECC) no início do período pré-parto de vacas mestiças $\mathrm{F} 1 \mathrm{HZ}$ durante as estações chuvosa e seca, de acordo com o tratamento e a base genética materna

\begin{tabular}{|c|c|c|c|c|c|}
\hline \multirow{3}{*}{ Variável } & \multicolumn{5}{|c|}{ Estação chuvosa } \\
\hline & \multirow{2}{*}{ Tratamento } & \multicolumn{3}{|c|}{ Base Genética Materna } & \multirow{2}{*}{ Média } \\
\hline & & Gir & Guzerá & Zebu & \\
\hline \multirow{3}{*}{ Peso inicial } & 1 & $534,60 \pm 54,72$ & $580,27 \pm 25,84$ & $600,67 \pm 9,24$ & $558,76 \pm 49,24$ \\
\hline & 2 & $533,75 \pm 46,54$ & $566,00 \pm 43,37$ & $505,00 \pm 0,00$ & $541,46 \pm 45,66$ \\
\hline & Média & $534,30 \pm 50,94$ & $576,47 \pm 30,38$ & $576,75 \pm 48,42$ & $553,40 \pm 48,29$ \\
\hline \multirow{3}{*}{ ECC inicial } & 1 & $3,41 \pm 0,18$ & $3,51 \pm 0,25$ & $3,67 \pm 0,35$ & $3,47 \pm 0,24$ \\
\hline & 3 & $3,41 \pm 0,26$ & $3,30 \pm 0,00$ & $3,30 \pm 0,00$ & $3,37 \pm 0,21$ \\
\hline & Média & $3,41 \pm 0,21$ & $3,45 \pm 0,24$ & $3,58 \pm 0,34$ & $3,44 \pm 0,23$ \\
\hline & \multicolumn{4}{|c|}{ Estação seca } & \\
\hline Variável & Tratamento & Gir & $\begin{array}{c}\text { Base Genética } \\
\text { Guzerá }\end{array}$ & Zebu & Média \\
\hline \multirow{3}{*}{ Peso inicial } & 1 & $548,00 \pm 60,85$ & $621,00 \pm 86,82$ & $536,00 \pm 34,08$ & $554,13 \pm 60,85$ \\
\hline & 2 & $515,43 \pm 58,31$ & $601,00 \pm 55,22$ & $560,00 \pm 14,42$ & $545,46 \pm 59,94$ \\
\hline & Média & $537,64 \pm 59,28^{B}$ & $611,00 \pm 65,99^{4}$ & $544,00 \pm 30,36^{B}$ & $551,08 \pm 59,84$ \\
\hline \multirow{3}{*}{ ECC inicial } & 1 & $3,90 \pm 0,36$ & $3,53 \pm 0,40$ & $3,67 \pm 0,35$ & $3,76 \pm 0,37$ \\
\hline & 2 & $3,90 \pm 0,36$ & $3,53 \pm 0,40$ & $3,67 \pm 0,35$ & $3,76 \pm 0,37$ \\
\hline & Média & $3,80 \pm 0,35$ & $3,77 \pm 0,41$ & $3,82 \pm 0,29$ & $3,80 \pm 0,34$ \\
\hline
\end{tabular}

A,B Médias, na mesma linha, seguidas de letras distintas, diferem entre si pelo teste $\mathrm{SNK}(\mathrm{P}<0,05)$.

Tabela 2: Peso $(\mathrm{kg})$ e escore da condição corporal (ECC) no final do período pré-parto, dias de permanência, ganho de peso e ganho de peso diário de vacas mestiças F1 HZ durante a estação chuvosa, de acordo com o tratamento e a base genética materna

\begin{tabular}{|c|c|c|c|c|c|}
\hline \multirow{2}{*}{ Variável } & \multirow{2}{*}{$\begin{array}{l}\text { Trata- } \\
\text { mento }\end{array}$} & \multicolumn{3}{|c|}{ Base genética } & \multirow{2}{*}{ Média } \\
\hline & & Gir & Guzerá & Zebu & \\
\hline \multirow{3}{*}{ Peso final } & 1 & $590,89 \pm 56,01$ & $629,58 \pm 32,95$ & $631,86 \pm 21,45$ & $609,80 \pm 48,85$ \\
\hline & 2 & $568,99 \pm 33,75$ & $620,43 \pm 44,66$ & $547,43 \pm 0,00$ & $583,16 \pm 43,20$ \\
\hline & Média & $583,27 \pm 49,73^{B}$ & $627,14 \pm 34,93^{A}$ & $610,75 \pm 45,70^{B}$ & $601,56 \pm 48,29$ \\
\hline \multirow{3}{*}{ ECC final } & 1 & $3,74 \pm 0,27$ & $3,95 \pm 0,32$ & $4,37 \pm 0,58$ & $3,89 \pm 0,37^{c}$ \\
\hline & 2 & $3,54 \pm 0,27$ & $3,73 \pm 0,51$ & $3,70 \pm 0,00$ & $3,61 \pm 0,34^{D}$ \\
\hline & Média & $3,67 \pm 0,28$ & $3,89 \pm 0,37$ & $4,20 \pm 0,58$ & $3,80 \pm 0,38$ \\
\hline \multirow{3}{*}{$\begin{array}{l}\text { Dias de } \\
\text { perma-nência }\end{array}$} & 1 & $38,47 \pm 5,29$ & $38,64 \pm 5,73$ & $37,00 \pm 8,19$ & $38,38 \pm 5,29$ \\
\hline & 2 & $35,13 \pm 8,49$ & $37,25 \pm 8,10$ & $29,00 \pm 0,00$ & $35,31 \pm 7,94$ \\
\hline & Média & $37,30 \pm 6,31$ & $38,27 \pm 6,16$ & $35,00 \pm 7,79$ & $37,43 \pm 6,29$ \\
\hline \multirow{3}{*}{$\begin{array}{l}\text { Ganho } \\
\text { peso }(\mathrm{kg})\end{array}$} & 1 & $59,29 \pm 26,36$ & $48,58 \pm 18,03$ & $31,00 \pm 20,45$ & $52,30 \pm 23,95$ \\
\hline & 2 & $35,24 \pm 31,17$ & $54,43 \pm 10,81$ & $42,43 \pm 0,00$ & $41,70 \pm 26,04$ \\
\hline & Média & $50,92 \pm 29,81$ & $50,14 \pm 16,27$ & $33,86 \pm 17,65$ & $49,02 \pm 24,79$ \\
\hline \multirow{3}{*}{$\begin{array}{l}\text { Ganho diário } \\
\text { (kg/dia) }\end{array}$} & 1 & $1,56 \pm 0,71$ & $1,25 \pm 0,41$ & $0,78 \pm 0,41$ & $1,36 \pm 0,62$ \\
\hline & 2 & $0,91 \pm 0,73$ & $1,51 \pm 0,10$ & $1,46 \pm 0,00$ & $1,13 \pm 0,66$ \\
\hline & Média & $1,33 \pm 0,77$ & $1,32 \pm 0,41$ & $0,95 \pm 0,48$ & $1,29 \pm 0,63$ \\
\hline
\end{tabular}

A,B Médias, na mesma linha, seguidas de letras distintas, diferem entre si pelo teste $\mathrm{SNK}(\mathrm{P}<0,05)$.

C, D Médias, na mesma coluna, para a mesma variável, seguidas de letras distintas, diferem entre si pelo teste de Wilcoxon $(P<0,05)$. 
Tabela 3: Peso (kg) e escore da condição corporal (ECC) no final do período pré-parto, dias de permanência, ganho de peso e ganho de peso diário de vacas mestiças F1 HZ durante a estação seca, de acordo com o tratamento e a base genética materna

\begin{tabular}{|c|c|c|c|c|c|}
\hline \multirow[t]{2}{*}{ Variável } & \multirow{2}{*}{$\begin{array}{l}\text { Trata- } \\
\text { mento }\end{array}$} & \multicolumn{3}{|c|}{ Base genética } & \multirow{2}{*}{ Média } \\
\hline & & Gir & Guzerá & Zebu & \\
\hline \multirow{3}{*}{ Peso final } & 1 & $618,46 \pm 49,75$ & $679,48 \pm 80,28$ & $598,45 \pm 54,34$ & $621,08 \pm 58,44$ \\
\hline & 2 & $560,20 \pm 46,89$ & $662,86 \pm 29,01$ & $627,00 \pm 40,30$ & $599,31 \pm 60,03$ \\
\hline & Média & $599,92 \pm 55,22^{B}$ & $671,17 \pm 54,75^{A}$ & $607,97 \pm 49,55^{B}$ & $613,43 \pm 58,44$ \\
\hline \multirow{3}{*}{ ECC final } & 1 & $4,45 \pm 0,36$ & $4,57 \pm 0,23$ & $4,17 \pm 0,56$ & $4,39 \pm 0,41^{C}$ \\
\hline & 2 & $4,14 \pm 0,27$ & $4,00 \pm 0,30$ & $4,43 \pm 0,23$ & $4,18 \pm 0,29^{D}$ \\
\hline & Média & $4,35 \pm 0,36$ & $4,28 \pm 0,39$ & $4,26 \pm 0,48$ & $4,32 \pm 0,39$ \\
\hline \multirow{3}{*}{$\begin{array}{l}\text { Dias de } \\
\text { perma- } \\
\text { nência }\end{array}$} & 1 & $37,80 \pm 10,23$ & $35,67 \pm 5,77$ & $38,50 \pm 20,02$ & $37,71 \pm 12,43$ \\
\hline & 2 & $33,86 \pm 17,33$ & $23,67 \pm 10,07$ & $42,00 \pm 25,24$ & $33,38 \pm 17,33$ \\
\hline & Média & $36,55 \pm 12,27$ & $29,67 \pm 9,85$ & $39,67 \pm 20,32$ & $36,19 \pm 14,25$ \\
\hline \multirow{3}{*}{$\begin{array}{l}\text { Ganho de } \\
\text { peso }(\mathrm{kg})\end{array}$} & 1 & $70,46 \pm 25,48$ & $58,48 \pm 7,19$ & $62,45 \pm 36,77$ & $66,96 \pm 26,77$ \\
\hline & 2 & $44,78 \pm 15,81$ & $61,86 \pm 35,12$ & $67,00 \pm 54,67$ & $53,85 \pm 30,59$ \\
\hline & Média & $62,29 \pm 25,58$ & $60,17 \pm 22,75$ & $63,97 \pm 39,97$ & $62,35 \pm 28,46$ \\
\hline \multirow{3}{*}{$\begin{array}{l}\text { Ganho } \\
\text { diário }(\mathrm{kg})\end{array}$} & 1 & $1,93 \pm 0,63$ & $1,65 \pm 0,17$ & $1,67 \pm 0,75$ & $1,83 \pm 0,62$ \\
\hline & 2 & $1,55 \pm 0,93$ & $3,53 \pm 3,62$ & $1,43 \pm 0,43$ & $1,98 \pm 1,86$ \\
\hline & Média & $1,81 \pm 0,74$ & $2,59 \pm 2,52$ & $1,59 \pm 0,64$ & $1,88 \pm 1,18$ \\
\hline
\end{tabular}

A, B Médias, na mesma linha, seguidas de letras distintas, diferem pelo teste SNK $(P<0,05)$.

C, D Médias, na mesma coluna, para a mesma variável, seguidas de letras distintas, diferem pelo teste de Wilcoxon $(P<0,05)$

Tabela 4: Peso e escore da condição corporal (ECC) ao parto $(\mathrm{kg})$ de vacas mestiças $\mathrm{F} 1 \mathrm{HZ}$ paridas durante as estações chuvosa e seca, de acordo com o tratamento e a base genética materna

\begin{tabular}{|c|c|c|c|c|c|}
\hline \multicolumn{6}{|c|}{ Estação chuvosa } \\
\hline \multirow[t]{2}{*}{ Variável } & \multirow{2}{*}{$\begin{array}{l}\text { Trata- } \\
\text { mento }\end{array}$} & \multicolumn{3}{|c|}{ Base genética } & \multirow{2}{*}{ Média } \\
\hline & & Gir & Guzerá & Zebu & \\
\hline \multirow{3}{*}{$\begin{array}{l}\text { Peso ao } \\
\text { parto }\end{array}$} & 1 & $530,33 \pm 52,48$ & $570,55 \pm 42,63$ & $584,33 \pm 33,86$ & $541,21 \pm 52,38^{c}$ \\
\hline & 3 & $505,00 \pm 44,77$ & $553,25 \pm 41,44$ & $494,00 \pm 0,00$ & $519,00 \pm 46,60^{\circ}$ \\
\hline & Média & $521,52 \pm 52,26$ & $565,93 \pm 41,58$ & $561,75 \pm 52,96$ & $541,21 \pm 52,38$ \\
\hline \multirow{3}{*}{$\begin{array}{l}E C C \text { ao } \\
\text { parto }\end{array}$} & 1 & $3,76 \pm 0,27$ & $4,01 \pm 0,40$ & $4,47 \pm 0,40$ & $3,93 \pm 0,40^{\mathrm{E}}$ \\
\hline & 3 & $3,50 \pm 0,21$ & $3,73 \pm 0,51$ & $3,70 \pm 0,00$ & $3,58 \pm 0,32^{F}$ \\
\hline & Média & $3,67 \pm 0,28$ & $3,93 \pm 0,43$ & $4,28 \pm 0,51$ & $3,82 \pm 0,40$ \\
\hline \multicolumn{6}{|c|}{ Estação seca } \\
\hline \multirow[t]{2}{*}{ Variável } & Trata- & & Base genética & & \multirow{2}{*}{ Média } \\
\hline & mento & Gir & Guzerá & Zebu & \\
\hline \multirow{3}{*}{$\begin{array}{l}\text { Peso ao } \\
\text { parto }\end{array}$} & 1 & $548,40 \pm 51,64$ & $603,00 \pm 78,56$ & $522,00 \pm 41,48$ & $548,86 \pm 56,08$ \\
\hline & 3 & $500,14 \pm 52,35$ & $577,33 \pm 59,00$ & $549,67 \pm 24,11$ & $529,38 \pm 56,78$ \\
\hline & Média & $533,05 \pm 55,59^{B}$ & $590,17 \pm 63,71^{A}$ & $531,22 \pm 37,58^{A B}$ & $541,86 \pm 56,08$ \\
\hline \multirow{3}{*}{$\begin{array}{l}\text { ECC ao } \\
\text { parto }\end{array}$} & 1 & $4,43 \pm 0,38$ & $4,43 \pm 0,23$ & $4,28 \pm 0,39$ & $4,39 \pm 0,36^{E}$ \\
\hline & 3 & $4,14 \pm 0,27$ & $4,00 \pm 0,30$ & $4,43 \pm 0,23$ & $4,17 \pm 0,29^{F}$ \\
\hline & Média & $4,34 \pm 0,37$ & $4,22 \pm 0,34$ & $4,33 \pm 0,34$ & $4,32 \pm 0,35$ \\
\hline
\end{tabular}

A, B Médias, na mesma linha, seguidas de letras distintas, diferem entre si pelo teste SNK $(P<0,05)$.

C, D Médias, na mesma coluna, para a mesma variável, seguidas de letras distintas, diferem entre si pelo teste $S N K(P<0,05)$.

E, F Médias, na mesma coluna, para a mesma variável, seguidas de letras diferentes, diferem pelo teste de Wilcoxon $(P<0,05)$. 
As diferenças de peso ao parto observadas entre as bases genéticas, durante as estações chuvosa e seca, podem refletir diferenças na aptidão leiteira e de deposição de gordura que existem entre raças taurinas e zebuínas e raças de leite e de corte. Vacas de raças taurinas leiteiras apresentam maior deposição de gordura visceral, além de maior peso visceral, o que reflete em maiores exigências nutricionais de mantença. Por outro lado, vacas de raças de corte apresentam maior deposição de gordura subcutânea, com menor peso visceral e menor exigência de mantença, efeitos que se sugerem, são mais marcantes em zebuínos e seus cruzamentos (Brahman) (Thompson et al., 1983; Solis et al., 1988; Ferrel e Jenkins, 1998).

Ao avaliar a curva de crescimento de fêmeas bovinas Guzerá, Gir, Holandês x Guzerá e Holandês x Gir, Perotto et al. (1997) observaram efeito da raça Guzerá sobre o tamanho e peso das fêmeas. Assim, as fêmeas de base Guzerá apresentaram maior peso adulto estimado, bem como maiores velocidade de ganho de peso e taxa de maturação. Esse maior peso adulto das fêmeas de base Guzerá está de acordo com os observados no presente trabalho, quando as vacas de base Guzerá foram mais pesadas.

Apesar de não ter sido observado efeito da suplementação no ganho de peso no período pré-parto, durante a estação chuvosa, houve efeito da suplementação sobre o escore da condição ao parto, que foi maior $(P<0,05)$ naquelas fêmeas suplementadas (Tabela 4). Apesar disso, há também que se considerar o escore da condição corporal em que os animais entraram no pré-parto. Durante a estação chuvosa, o escore inicial médio foi de $3,44 \pm 0,23$ (Tabela 1). Por outro lado, durante a estação seca, o escore inicial médio foi de $3,80 \pm 0,34$ (Tabela 1). Esses escores são considerados satisfatórios, diante da recomendação de escore ao parto de 3,5 a 4,0 (Ferreira, 1991). Dessa forma, vale considerar o adequado manejo a que foram submetidos os animais durante o final da lactação e início

\section{Referências}

BELL, A. W. Regulation of organic nutrient metabolism during transition from late pregnancy to early lactation. J. Anim. Sci., v. 73, p. 28042819, 1995.

CARVALHO, B. C. Efeito da base genética materna, sistema de suplementação durante a recria e estação de parição sobre variáveis produtivas e reprodutivas de fêmeas primíparas Holandês $x$ Zebu. Dissertação: Mestrado em Medicina Veterinária. Belo Horizonte: EVUFMG, 2004, $60 \mathrm{fl}$.

FAEMG. Diagnóstico da pecuária leiteira do estado de Minas Gerais em 2005. Belo Horizonte: FAEMG, 2006, 156 p.

FERREIRA, A. M. Manejo reprodutivo e eficiência da atividade leiteira. Coronel Pacheco: Embrapa-CNPGL, 1991, 47 p.

FERREIRA, J. J. Alimentação de bovinos mestiços leiteiros. Inf. Agropec.o, v. 25, n. 221, p. 64-72, 2004.

FERREL, C. L. E JENKINS, T. G. Relationships among various body components of mature cows. J. Anim. Sci., v. 58, p. 222-243, 1984.

FERREL, C. L. E JENKINS, T. G. Cow type and the nutritional environment: nutritional aspects. J. Anim. Sci., v. 61, p. 725-74, 1985.

FERREL, C. L. E JENKINS, T. G. Body composition and energy utilisation by steers of diverse genotypes fed a high-concentrate diet during do período seco, que assegurou um adequado escore na entrada do período pré-parto.

Outra consideração necessária é sobre a época do parto e sua influência sobre o período de encerramento da lactação e o período seco. Vacas com partos previstos para a estação chuvosa, nos meses de novembro a março, geralmente são alimentadas, no final do período seco, com volumosos de qualidade inferior, o que coincide com o final da lactação e menor produtividade. Após a secagem, essas vacas deixam de ser suplementadas, devido ao início do período chuvoso. Contudo, no início desse período observa-se menor disponibilidade de pastagens. Por outro lado, vacas com partos previstos para a estação seca, encerram a lactação durante o período chuvoso anterior, o que coincide, geralmente, com o período de maior disponibilidade e qualidade das pastagens. Além disso, devido ao início do período seco, as vacas são suplementadas com volumoso no pré-parto. Essas considerações refletem sobre diferenças no escore da condição corporal ao parto entre estações do ano. Em trabalhos que avaliaram o efeito da época do parto, em vacas mestiças F1 Holandês x Zebu, Saulytis (2004) e Carvalho (2005) observaram maiores escores nas vacas que pariram durante a estação seca. Essas diferenças sugerem que, durante a estação chuvosa, deve-se dar ainda mais atenção ao manejo da condição corporal no final da lactação e início do período seco, com a suplementação com concentrado podendo ser feita de forma estratégica.

\section{Conclusões}

O adequado manejo nutricional, com volumosos de boa qualidade, de vacas mestiças durante o período pré-parto é suficiente para garantir adequados escores da condição corporal ao parto. Contudo, a suplementação com concentrado promove maiores peso e escore da condição corporal ao parto, devendo ser utilizada de forma estratégica no pré-parto, principalmente na estação chuvosa.

the finishing period: I. Angus, Belgian Blue, Hereford and Piedmontese steers. J. Anim. Sci., v. 76, p. 637-646, 1998.

PEROTTO, D; CASTANHO, M. J. P.; ROCHA, J. L.;PINTO, J. M. Descrição das curvas de crescimento de fêmeas bovinas Guzerá, gir, Holandês x Guzerá e Holandês x Gir. Rev. Bras. Zootec., v. 26, p. 283-288, 1997.

SAEG, v. 9.1. UFV.

SAUYLITYS, F. C. F. Efeito da origem, base maternal zebuína, origem e época de ocorrência dos partos de fêmeas F1 Holandês-Zebu sobre variéveis biométricas, reprodutivas e produtivas. Dissertação: Mestrado em Medicina Veterinária. Belo Horizonte: EV-UFMG, 2004. $106 \mathrm{fl}$.

SOLIS, J. C., BYERS, F. M.; SCHELLING, G. T.; LONG, C. R. E GREENE, L. W. Maintenance requirements and energetic efficiency of cows of different breed types. J. Anim. Sci., v. 66, p. 764-773, 1988.

STOCKDALE, C. R. E TRIGG, T. E. Effect of pasture feeding levels on the responses of lactating dairy cows to high energy supplements. Australian J. Exp. Agric., v. 29, p. 605-611, 1989.

THOMPSON, W. R.; MEISKE, J. C.; GOODRICH, R. D.; RUST, J. R. E BYERS, F. M. Influence of body composition on energy requirements of beef cows during winter. J. Anim. Sci., v. 56, p. 1241-1251, 1983. ZOCCAL, R. Estatísticas do leite. Disponível em: http://www.cnpgl. embrapa.br/nova/informacoes/estatisticas/producao/producao.php. Acessado em 20/08/2009. 